\title{
Effectiveness of an Attenuated Zucchini yellow mosaic virus Isolate for Cross-Protecting Cucumber
}

\author{
Yoshitaka Kosaka, Kyoto Prefectural Institute of Agricultural Biotechnology, Kyoto 619-0244; Bo-Song \\ Ryang, Laboratory of Plant Pathology, Graduate School of Agriculture and Biological Sciences, Osaka Pre- \\ fecture University, Osaka 599-8531; Takashi Kobori, Kyoto Prefectural Institute of Agricultural Biotechnol- \\ ogy, Kyoto 619-0244; Hiroshi Shiomi, Takii Plant Breeding and Experimental Station, Shiga 520-3231; \\ Hisao Yasuhara, Kyoto Biken Laboratories, Inc., Kyoto 611-0041; and Mitsunobu Kataoka, Kyoto Prefec- \\ tural Institute of Agricultural Biotechnology, Kyoto 619-0244, Japan
}

\begin{abstract}
Kosaka, Y., Ryang, B.-S., Kobori, T., Shiomi, H., Yasuhara, H., and Kataoka, M. 2006. Effectiveness of an attenuated Zucchini yellow mosaic virus isolate for cross-protecting cucumber. Plant Dis. 90:67-72.

To cross-protect cucumber plants from Zucchini yellow mosaic virus (ZYMV), we used cold treatment to obtain an attenuated isolate of ZYMV, designated ZYMV-2002. ZYMV-2002 was obtained from a virulent ZYMV isolate after repeated low temperature treatment at 12.5 to $15^{\circ} \mathrm{C}$ followed by five cycles of single-plant transfer. The isolate produced very mild or no symptoms on cucurbit plants. In addition, inoculated cucumber plants had very similar fruit productivity to healthy control plants under field conditions. During field experiments in 2002 and 2003, when other viruses were also present, protected plants significantly suppressed infection with ZYMV, progression of disease severity, and reduction of fruit yield and quality. These results demonstrate that ZYMV 2002 is a potentially useful attenuated ZYMV isolate for reducing the impact of ZYMV.
\end{abstract}

Zucchini yellow mosaic virus (ZYMV) is an aphid-borne potyvirus that causes serious damage to cucurbit crops worldwide (3). In Japan, cucumbers (Cucumis sativus L.) are commonly affected by ZYMV during summer to early autumn. Infected plants exhibit severe mosaic and distortion on leaves and fruits, or wilting in grafted plants (5).

Recently, a mild variant of ZYMV, ZYMV-WK, has been used commercially in several countries to control the severe disease caused by ZYMV in cucurbits (14). This cross-protection strategy with ZYMV-WK has been successfully applied to over 2,500 ha of cucurbits in Israel since 1996 (18). However, the importation of any plant viruses to Japan is prohibited by the

Corresponding author: Yoshitaka Kosaka E-mail: kosaka@kab.seika.kyoto.jp

Nucleotide sequence data for two ZYMV isolates Z5-1 and 2002 are available in the GenBank database under accession numbers AB188115 and AB188116.

*The $e$-Xtra logo stands for "electronic extra" and indicates that Figure 1 appears in color in the on-line edition.

Accepted for publication 14 August 2005.

DOI: 10.1094/PD-90-0067

(C) 2006 The American Phytopathological Society
Plant Protection Law, except for use in research, because plant viruses have a risk of causing economic losses to agricultural production. Japan is endowed with a wide range of climates and geographies, thus a great variety of agricultural crops are grown throughout the country. Therefore, we cannot distribute ZYMV-WK as a biological agent in Japan even though the virus is a very mild isolate.

An attenuated ZYMV isolate, ZY95 (11), has only been used by cucumber growers in Kyoto Prefecture of Japan where the potential risk of lethal wilt syndrome is high (8). However, this isolate has been applied to a limited number of fields because it only prevents severe wilt symptoms but still induces chlorotic spots and/or slight malformation on fruits. There are no other methods to protect crops. Thus, growers need an alternative attenuated isolate that minimizes the marketable yield reductions that often occur as a result of protective inoculation.

Therefore, our research objective was to develop a new attenuated ZYMV isolate that causes less detrimental effects on fruit yield and quality than inoculation with ZY95. In this paper, we report the effectiveness of an attenuated ZYMV isolate obtained by cold treatment on the cross-protection of cucumber plants from ZYMV infection.

\section{MATERIALS AND METHODS}

Virus isolates and inoculum sources. Two ZYMV isolates, Z5-1 (11) and KAMO, Watermelon mosaic virus (WMV) (11), and Papaya ring spot virus (PRSV) were isolated from diseased cucumber plants in Kyoto Prefecture. An attenuated ZYMV isolate was then obtained from Z5-1 by cold treatment. Leaves infected with each isolate were ground in $0.1 \mathrm{M}$ phosphate buffer ( $\mathrm{pH}$ 7.2) and diluted $1: 10$ (wt/vol) with buffer. Carborundum-dusted cotyledons of 7- to 8-dayold seedlings were mechanically inoculated by rubbing with cotton swabs dipped in the sap inoculum. After inoculation, the leaves were immediately rinsed with tap water, and the inoculated plants were kept in a temperaturecontrolled greenhouse $\left(25^{\circ} \mathrm{C}\right)$. The attenuated ZYMV isolate, two ZYMV isolates and PRSV, and WMV were propagated in pumpkin (Cucurbita maxima Duchesne cv. Ebisu), cucumber (cv. Sagamihanjiro), and bean (Phaseolus vulgaris L.), respectively. Each of the infected leaves was taken 17 to 20 days after inoculation and stored at $-80^{\circ} \mathrm{C}$ before being used as an inoculum source. Purified virus preparation $(50 \mu \mathrm{g} / \mathrm{ml})$ of the Cucumber mosaic virus (CMV) Pepo isolate (16) was used in mixed inoculation with the attenuated or Z5-1 ZYMV isolate.

Cold treatment. Pumpkin seedlings grown in a greenhouse in 0.8 -liter pots containing commercial potting mix were mechanically inoculated with Z51 when the cotyledons were just fully expanded. After inoculation, the seedlings were transferred into a growth cabinet maintained at 12.5 or $15^{\circ} \mathrm{C}$ with a $16-\mathrm{h}$ photoperiod, at about $15,000 \mathrm{~lx}$ for 30 to 60 days. Leaves from treated plants were stored at $-80^{\circ} \mathrm{C}$ and then used for single-lesion transfers with Chenopodium quinoa Willd. or singleplant transfers with pumpkin using sap inoculum diluted 1:500 to 4,000 (wt/vol) with $0.1 \mathrm{M}$ phosphate buffer. Symptom development was monitored for 20 to 30 days in each pumpkin plant after inoculation in a greenhouse. To 
check for ZYMV, all plants showing no or faint symptoms were tested by the double-antibody sandwich (DAS-) (2) or rapid non-precoated indirect (I-) (6) enzyme-linked immunosorbent assay (ELISA) method with antiserum against ZYMV.

Relative virus accumulation. DASELISA was used to determine the relative virus concentrations in three true leaves after inoculation to cotyledons of cucumber (cv. Tsuyataro) plants grown in a greenhouse. Three leaf disks (6 $\mathrm{mm}$ diameter) per leaf were collected from six plants 24 days after inoculation and assayed by DAS-ELISA at a dilution of 1:20 (wt/vol) with buffer (phosphate-buffered saline [PBS],

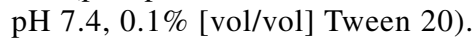

Aphid transmission. Aphids (Aphis gossypii Glover) were reared on healthy pumpkin plants. They were starved for 1.5 to $2 \mathrm{~h}$, then placed on cucumber or pumpkin leaves infected with either the attenuated or the Z5-1 isolate of ZYMV. After a 5- to 10-min acquisition feeding period, 6 to 15 aphids were transferred to each healthy seedling of cucumber or pumpkin (4 to 10 plants per test), allowed to feed for $3 \mathrm{~h}$, then killed with dichlorvos (DDVP). Twenty days after inoculation, plants that did not show any symptoms were tested for ZYMV by DAS-ELISA.

Fruit productivity. To evaluate the effects of protective inoculation with the attenuated isolate on fruit production in grafted cucumber plants, cucumber (cv. Tsuyataro) seedlings were grown and protective-inoculated at the Kansai nursery (Takii \& Co., Ltd., Mie, Japan). One day after inoculation, these seedlings were grafted to rootstocks of squash ( $C$. moschata Duchesne cv. Sherpa) by the Takii's pin-grafting method (cutting-grafts). Leaf extracts (1 $\mathrm{g}$ per $5 \mathrm{ml}$ of buffer) and a 30-fold diluted solution of concentrated sap preparation obtained by ultra-filtration with MiniKros Sampler System (400 $\mathrm{kDa}, 245 \mathrm{~cm}^{2}$ ) (Spectrum Laboratories Inc, Laguna Hills, CA) were used as inocula in the 2002 and 2003 experiments, respectively. Noninoculated control seedlings were treated with buffer only. Grafted plants were maintained according to the standard practices of Takii. All inoculated seedlings were tested by DAS-ELISA using small leaf samples (approximately $0.2 \mathrm{~g}$ ) collected from the first and second true leaves before planting.

Twenty-six days after grafting, on 20 May 2002, the seedlings were transplanted to a field at the Institute. Similarly, 16 days after grafting, on $14 \mathrm{Au}$ gust 2003, the seedlings were transplanted to an aphid-proof plastic house at the Institute. Each plot was established in 2 rows and the seedlings were transplanted at $0.9-\mathrm{m}$ intervals in rows $1.5 \mathrm{~m}$ apart. Fruit were collected every 1 or 2 days from 21 plants (7 plants, 3 replications) and 16 plants (4 plants, 4 replications) of the 2002 and 2003 experiments, respectively. All plants were maintained according to the Kyoto prefectural standard practices for cucumbers.

Cross-protective ability. Greenhouse evaluation. Experiments were conducted using nongrafted cv. Tsuyataro seedlings grown in 1.2-liter pots in a greenhouse. The cotyledons of 8 day-old seedlings were inoculated with the attenuated isolate; control seedlings were treated with buffer only. Ten days after inoculation, the first true leaves were mechanically inoculated with crude leaf extracts (diluted 1:50 or $1: 200$ [wt/vol] with buffer) from plants infected with Z5-1 or KAMO. Observations of symptom development were made 10,15 , and 20 days after challenge inoculation. Plants showing indistinct or no symptoms at the final observation were assayed by back-inoculation to $C$. quinoa or by I-ELISA.

Field evaluation. In order to demonstrate the effectiveness of the attenuated ZYMV isolate under natural infection conditions, field experiments were conducted at the Institute and unreplicated observational studies were conducted in grower's fields in Ujidawara and Kamo. All sites are in the southern part of Kyoto Prefecture. These experiments consisted of protective- and noninoculated (control) plots with grafted seedlings. After inoculation, all seedlings or randomly selected seedlings were tested by DAS-ELISA before planting.

At the Institute in Seika, seedlings were transplanted to a field on 20 May 2002 (27 days after inoculation) and 21 May 2003 (20 days after inoculation). Protective- and noninoculated seedlings were planted in plots at $1-\mathrm{m}$ intervals in 2 rows $1.5 \mathrm{~m}$ apart; 14 plants (7 plants, 2 replications) and 20 plants (5 plants, 4 replications) in the 2002 and 2003 experiments, respectively. Each inoculated plot was adjacent to 2 control plots and diagonally across from another inoculated plot. To ensure distribution of the KAMO isolate, the infected plants grown in 3-liter pots were placed between two rows ( 2 and 4 plants in 2002 and 2003, respectively), and then about 20 aphids (A. gossypii) were transferred to each plant. About 1 month later, these inoculum sources were removed. The plants surveyed were treated regularly with fungicide and insecticide. Marketable fruits of regular shape were counted every 1 or 2 days and classified individually based on the commercial grading standards for cucumbers as either normal, mild viral symptoms such as chlorotic spots and/or slight malformation, or high, no visible viral symptoms.

At Ujidawara, on 21 June 2003 (20 days after inoculation), 100 inoculated and 400 noninoculated seedlings were transplanted at $1-\mathrm{m}$ intervals in 2 respective rows spaced $1.4 \mathrm{~m}$ apart. At Kamo, on 25 July 2003 (17 days after inoculation), 200 inoculated seedlings were transplanted in the plot at $1-\mathrm{m}$ intervals in rows spaced $1.5 \mathrm{~m}$ apart. One hundred noninoculated seedlings were also transplanted in the plot adjacent to the inoculated plot. The plots were not replicated at each site. The plants in each field were maintained according to local standard practices.

Disease progression was surveyed in all plants five times (at the Institute) or in 50 randomly selected plants from each plot 79 (Ujidawara) and 69 (Kamo) days after transplanting. Plants were scored for disease severity according to the following scale: 1 , very mild mosaic or chlorotic spots; 2 , mild mosaic or mild yellow mosaic; 3 , yellow mosaic without leaf distortion or malformation; 4 , severe yellow mosaic with deformed leaves and fruits; 5 , grade 4 plus stunting and necrosis or wilting. Leaf samples were collected from plants surveyed in the three locations and divided into three portions for DAS-ELISA and reverse transcriptasepolymerase chain reaction (RT-PCR). The incidence of $\mathrm{CMV}$, WMV, and PRSV in the field samples was determined by DAS-ELISA.

RT-PCR. Total RNA was extracted from the field samples using ABI Prism 6100 Nucleic Acid PrepStation (Applied Biosystems, Foster City, CA). First-strand cDNAs were synthesized using a cDNA synthesis kit (FirstStrand cDNA Synthesis Kit; Amersham Biosciences, Buckinghamshire, UK) and primer 3093R (5'-ATGCTCTTCGCATGTACTCG-3'; 2.5 pmol) according to the manufacturer's instructions.

Specific primers for differentiation between the promising attenuated and two ZYMV isolates, Z5-1 and Kamo, were prepared based on a difference in the 2,046th nucleotide position of the helper component-protease (HC-Pro) sequence (17). The forward primers SZ199-F (5'-TCTGGTGATCCAAAGTACATTGAATT-3') and AZ199-F (5'TCTGGTGATCCAAAGTACATTGAATC-3') were used for Z5-1 and Kamo, and attenuated isolates, respectively, and the reverse primer 1ZR (5'CAACATCCATCAACGAAGGC-3') was used for amplification. PCR was performed in a reaction mixture containing the following: $1 \mu \mathrm{l}$ of cDNA solution, $1.5 \mu \mathrm{l}$ of GeneAmp 10× PCR buffer (Applied Biosystems), $0.6 \mu \mathrm{l}$ of $2.5 \mathrm{mM}$ dNTP mix, $1.5 \mu$ of $25 \mathrm{mM} \mathrm{MgCl}_{2}, 0.3$ 
$\mu \mathrm{l}$ of $25 \mu \mathrm{M}$ of each forward and reverse primer, $0.15 \mu$ of AmpliTaq Gold DNA Polymerase LD (Applied Biosystems), and $9.65 \mu \mathrm{l}$ of sterile distilled water, under the following conditions: 7 $\min$ at $95^{\circ} \mathrm{C}, 15 \mathrm{~s}$ at $95^{\circ} \mathrm{C}$, and $1 \mathrm{~min}$ at $67^{\circ} \mathrm{C}$ for 40 cycles (GeneAmp PCR System 9700; Applied Biosystems). PCR products were then electrophoresed in 3\% agarose gel.

Data analysis. Disease severity, disease incidence, and marketable fruits were statistically analyzed with the Mann-Whitney $U$ test, Fisher's exact test, or chi-square test of independence, and the $t$ test, respectively.

\section{RESULTS}

Derivation of an attenuated isolate by cold treatment. After inoculation with the original isolate Z5-1, pumpkin seedlings were immediately grown at low temperatures $\left(12.5^{\circ} \mathrm{C}\right)$ for 60 days. After single-lesion transfers, one out of the 20 single-lesion isolates (SLIs) induced slightly milder symptoms than Z5-1. In a second screening trial, seedlings inoculated with this SLI were maintained at $15^{\circ} \mathrm{C}$ for 30 days and then at $12.5^{\circ} \mathrm{C}$ for 35 days. Of the 119 SLIs obtained, one caused a distinctly milder symptom than the others. Subsequently, 13 days after inoculation with this isolate, infected plants were kept at $15^{\circ} \mathrm{C}$ for 35 days and then at $12.5^{\circ} \mathrm{C}$ for 35 days. One of the resultant 24 SLIs induced a mosaic symptom without malformation and rarely produced local lesions on $C$. quinoa. Of the few SLIs that originated from this milder isolate, a mild candidate was selected. In addition, seedlings 10 days after inoculation with the candidate were maintained at $15^{\circ} \mathrm{C}$ for 30 days and then at $12.5^{\circ} \mathrm{C}$ for 30 days, followed by five cycles of singleplant transfers using pumpkin seedlings. As a result of this screening trial, we obtained a promising mild isolate designated ZYMV-2002.

Table 1. Symptoms observed on several plants infected with two Zucchini yellow mosaic virus (ZYMV) isolates ${ }^{\mathrm{a}}$

\begin{tabular}{lcc}
\hline Plant (cultivar) & $\begin{array}{c}\text { ZYMV- } \\
\mathbf{2 0 0 2}\end{array}$ & Z5-1 \\
\hline Cucumber & $\mathrm{vm}$ & $\mathrm{Ml}$ \\
(Tsuyataro) & & \\
(Sagamihanjiro) & $\mathrm{vm}$ & $\mathrm{Ml}$ \\
Melon (Lewis) & - & $\mathrm{Ml}, \mathrm{Ns}$ \\
Pumpkin (Ebisu) & $\mathrm{vm}$ & $\mathrm{Ml}, \mathrm{Ns}$ \\
Squash (Sherpa) & - & $\mathrm{Ml}, \mathrm{Ns}$ \\
Watermelon (Kabuki) & - & $\mathrm{Ml}$ \\
Zucchini (Diner) & $\mathrm{vm}$ & $\mathrm{Ml}$ \\
Chenopodium quinoa & 1 & $\mathrm{~L}$ \\
\hline
\end{tabular}

${ }^{\text {a }}$ Symptoms were observed for 3 weeks after inoculation. $\mathrm{vm}=$ very mild mosaic; $\mathrm{Ml}=$ severe mosaic and malformation; Ns $=$ necrotic spot; $\mathrm{L}=$ chlorotic and subsequent necrotic local lesion; 1 = symptomless local infection; $-=$ no symptoms.
ZYMV-2002 and Z5-1 caused different symptoms on the eight test plants (Table 1). Z5-1 induced severe mosaic and malformed symptoms on all cucurbit plants tested, including cucumber, net melon ( $C$. melo L.), pumpkin, squash, watermelon (Citrullus lanatus (Thunb.) Matsum. \& Nakai), and zucchini (C. pepo L.). On the other hand, ZYMV-2002 produced only very mild or no symptoms on these plants (Fig. 1). The isolate also did not produce local lesions on inoculated leaves of $C$. quinoa. It was confirmed to be present by tissue blot immunoassay (data not shown).

DAS-ELISA values for the second, third, and fourth true leaves of cucumindicated that replication of ZYMV2002 was substantially less than Z5-1 and was slightly suppressed by coinfection with CMV (Fig. 2). CMV ber plants 24 days after inoculation

accumulation was not affected by coinoculation with ZYMV-2002, while it was significantly increased by the presence of Z5-1 (Fig. 2). In addition, WMV or PRSV accumulation was not substantially increased by coinoculation with this mild isolate (data not shown). Symptoms on plants dually inoculated with ZYMV-2002 and either CMV, WMV, or PRSV were similar to those on plants singly inoculated with CMV, WMV, or PRSV, respectively (data not shown).

Fruit productivity. We evaluated the effects of the tentative mild isolate ZYMV-2002 on fruit production under two different conditions. In the field experiment, no symptoms typical of ZYMV strains were observed, although symptoms typical of either CMV or WMV were found in a few plants in both inoculated and noninoculated plots at a later stage. ZYMV-2002 was not

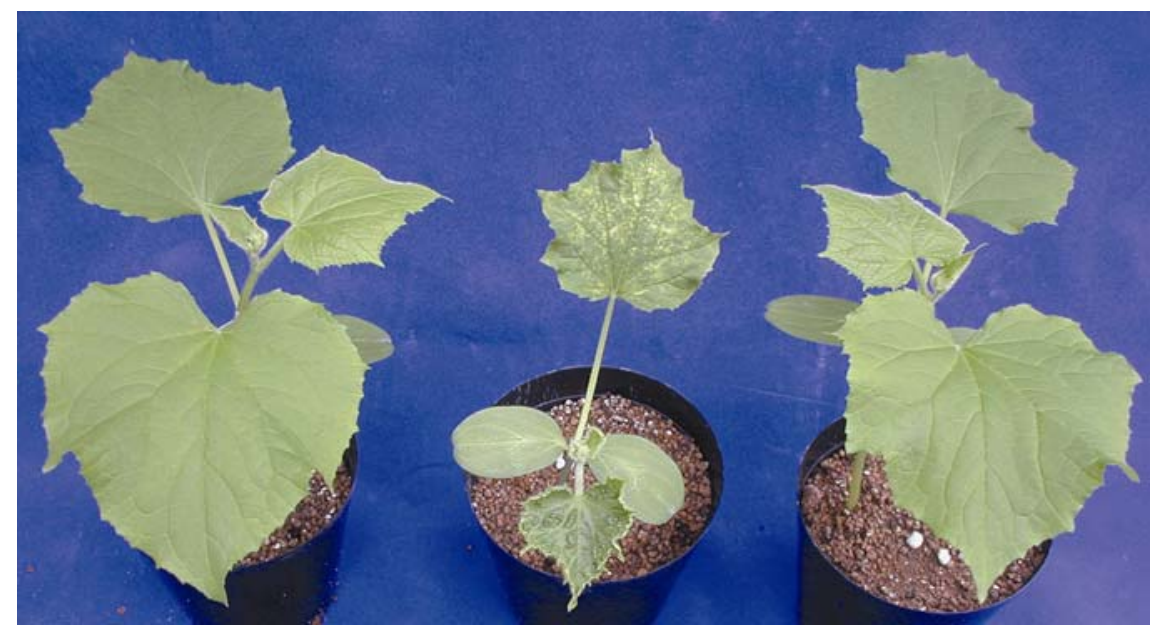

Fig. 1. Symptoms on cucumber cv. Tsuyataro caused by two Zucchini yellow mosaic virus (ZYMV) isolates 14 days after inoculation. Left to right: plants infected with ZYMV-2002, with Z5-1, and noninoculated plants.

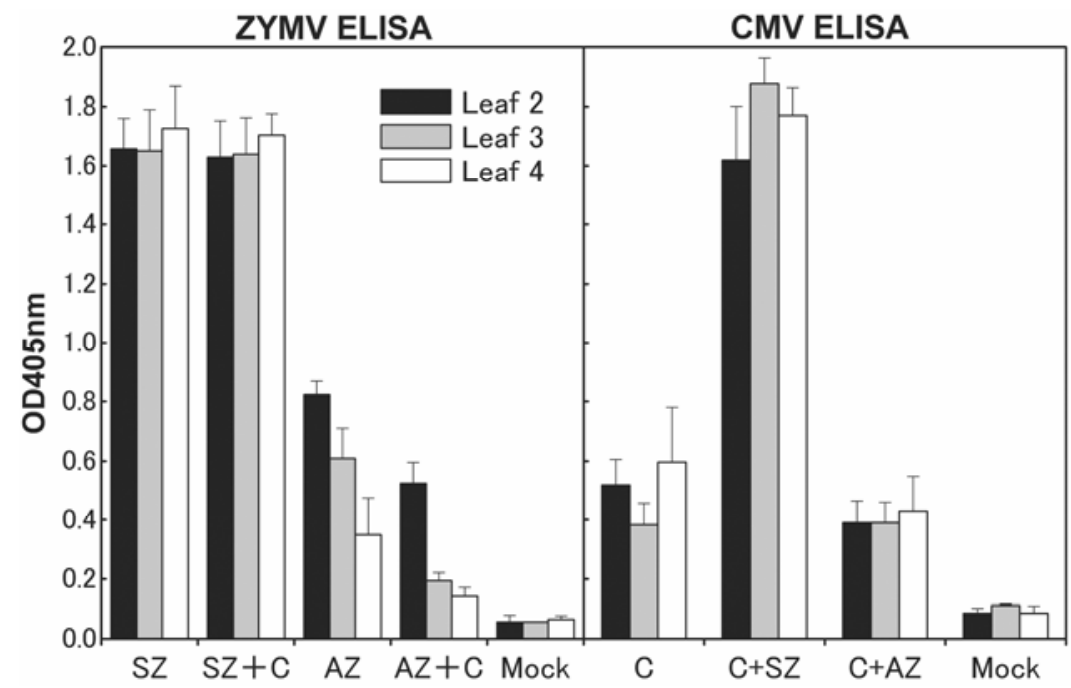

Fig. 2. Relative virus accumulation in the second, third, and fourth true leaves of cucumber cv. Tsuyataro plants 24 days after inoculation. Vertical bars indicate standard errors of means. $\mathrm{SZ}=\mathrm{Z5}-1, \mathrm{AZ}=\mathrm{ZYMV}-2002, \mathrm{C}=$ Cucumber mosaic virus, Mock $=$ healthy plants inoculated with buffer only. 
detected in the control plot. None of the plants infected with ZYMV-2002 alone exhibited viral symptoms on their leaves or fruit. In addition, the inoculated plants infected with CMV or WMV did not produce more prominent mosaic symptoms than the noninoculated plants that were singly infected with CMV or WMV (data not shown). There were no significant differences in the number and percentage of symptomless and regular fruits between inoculated and noninoculated plants (Table 2). In the second experiment, which was performed in an aphidproof plastic house with no detectable virus infection, the inoculated plants did not show significant reduction of fruit yield or quality (Table 2). However, the inoculated plants occasionally induced very mild mosaic symptoms on newly developed leaves beginning in mid-September. These results showed that ZYMV-2002 had no detrimental effects on cucumber fruit yield or quality.

Aphid transmissibility. Aphid transmission tests with A. gossypii were repeated four times. Transmission of ZYMV-2002 was not evident based on the 46 plants exposed to aphids carrying this isolate. However, Z5-1 was symptoms or serological tests in any of

efficiently transmitted, being detected in 35 of 44 plants tested.

Cross-protective ability. The ability of ZYMV-2002 to protect against mechanical challenge inoculation of two ZYMV isolates, Z5-1 and KAMO, was evaluated in a greenhouse. Cucumber plants inoculated with ZYMV-2002 apparently delayed and suppressed the expression of mosaic symptoms and/or deformed leaves characteristic of challenge viruses during the period tested, although the cross-protection was incomplete (Table 3). Neither Z5-1 nor KAMO was detected from symptomless plants. When KAMO was used as the challenge virus, cross-protection effectiveness was likely affected by the degree of inoculum dilution.

Differentiation of ZYMV-2002 from ZYMV isolates by RT-PCR analysis. RT-PCR analysis using primers AZ199-F and 1ZR yielded a DNA fragment of the expected size (199 bp) from cucumber leaves infected only with ZYMV-2002. In contrast, amplification with primers SZ199 and 1ZR yielded DNA fragments in Z5-1 and KAMO, but no detectable products from ZYMV-2002 (Fig. 3).

Field evaluation. Figure 4 shows results of the field experiments at the Institute where plants infected with the

Table 2. Effect of inoculation with Zucchini yellow mosaic virus (ZYMV)-2002 on cucumber fruit production

\begin{tabular}{|c|c|c|c|c|}
\hline \multirow[b]{3}{*}{ Treatment } & \multicolumn{4}{|c|}{ Marketable fruit (symptomless and regular shape) ${ }^{a}$} \\
\hline & \multicolumn{2}{|c|}{ Exp. $1^{b}$} & \multicolumn{2}{|c|}{ Exp. $2^{\mathrm{b}}$} \\
\hline & Fruits per plant & $\%$ fruit $^{\mathrm{c}}$ & Fruits per plant & $\%$ fruit $^{\mathrm{c}}$ \\
\hline Noninoculated & 135.0 & 79.5 & 106.9 & 72.6 \\
\hline 2002-inoculated & 132.0 & 79.0 & 104.9 & 70.5 \\
\hline
\end{tabular}

Table 3. Cross-protection with Zucchini yellow mosaic virus (ZYMV)-2002 against two ZYMV isolates in cucumber ${ }^{\mathrm{a}}$

\begin{tabular}{|c|c|c|c|c|c|c|}
\hline \multirow{2}{*}{$\begin{array}{l}\text { ZYMV } \\
\text { isolate }\end{array}$} & \multirow{2}{*}{$\begin{array}{l}\text { Inoculum } \\
\text { dilution }\end{array}$} & \multirow[b]{2}{*}{ Treatment } & \multirow{2}{*}{$\begin{array}{l}\text { Plants } \\
\text { tested }\end{array}$} & \multicolumn{3}{|c|}{$\%$ diseased plants [severity rating $]^{b}$} \\
\hline & & & & 10 days & 15 days & 20 days \\
\hline \multirow[t]{4}{*}{$\mathrm{Z5}-1$} & 50 -fold & Preinoculated & 10 & 0 & 0 & $10[1]$ \\
\hline & & Noninoculated & 8 & $100[2]$ & $100[4]$ & $100[5]$ \\
\hline & 200 -fold & Preinoculated & 10 & 0 & 0 & $10[1]$ \\
\hline & & Noninoculated & 8 & $87.5[2]$ & $87.5[4]$ & $87.5[5]$ \\
\hline \multirow[t]{4}{*}{ KAMO } & 50 -fold & Preinoculated & 25 & 0 & $8[1]$ & $40[2-3]$ \\
\hline & & Noninoculated & 10 & $80[1]$ & $80[3]$ & $80[4]$ \\
\hline & 200 -fold & Preinoculated & 25 & 0 & 0 & 0 \\
\hline & & Noninoculated & 10 & $60[1]$ & $60[3]$ & $60[4]$ \\
\hline
\end{tabular}

a Ten days after the protective-preinoculation, the first true leaves were mechanically inoculated with crude leaf extracts (diluted 1:50 or 1:200 [wt/vol] with buffer) carrying Z5-1 or KAMO. Observations of symptom development were made 10, 15, and 20 days after the challenge inoculation. Plants inoculated with the attenuated isolate produced no symptoms during the experiment.

${ }^{\mathrm{b}}$ Symptom severity on diseased plants: $1=$ mild chlorotic spots; $2=$ prominent vein-clearing or mild mosaic; $3=$ mosaic; $4=$ mosaic and mild malformation; $5=$ severe mosaic and malformation.
KAMO isolate were used as inoculum sources. In both years, CMV simultaneously occurred. Incidence of CMV averaged 57.1 and $35.0 \%$ in the control plots and 21.4 and $20 \%$ in the inoculated plots at the final assessments in 2002 and 2003, respectively. In the noninoculated control plots, disease progression curves from the 2002 and 2003 experiments were similar. Symptoms characteristic of ZYMV such as prominent vein-clearing first appeared in late June (about 1 month after transplanting), and subsequently disease severity rapidly increased. At about 50 days after transplanting in both experiments, all plants were infected with ZYMV and produced severe yellow mosaic symptoms with deformed leaves and fruits. Wilting and death due to wilting were observed in 21.4 and $15 \%$ of the plants in the 2002 and 2003 experiments, respectively. ZYMV-2002 was detected by RT-PCR analysis from only one plant on 20 July 2003 in a control plot.

On the other hand, in the plots inoculated with ZYMV-2002, almost all plants had no symptoms at about 40 days after transplanting. Ten days later, 28.6 and $20 \%$ of the plants developed mild mosaic or yellow mosaic symptoms in the 2002 and 2003 experiments, respectively. RT-PCR analysis showed that these diseased plants were infected with KAMO (data not shown). Number

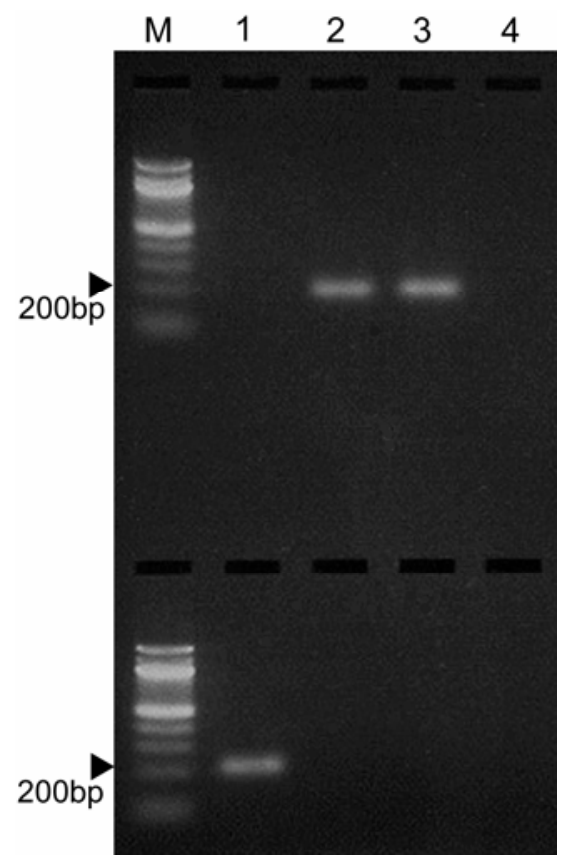

Fig. 3. Specific detection of three Zucchini yellow mosaic virus (ZYMV) isolates by reverse transcriptase-polymerase chain reaction analysis of total RNA extracts using primers SZ199-F and 1ZR (upper lanes) or AZ199-F and 1ZR (lower lanes), which amplify a 199-bp product. Lane $\mathrm{M}=1-\mathrm{kb}$ DNA ladder; lane 1 = ZYMV-2002; lane $2=$ Z5-1; lane $3=\mathrm{KAMO}$; lane $4=$ healthy cucumber leaves. 
of symptomatic plants in the protectiveinoculated plots appeared to increase gradually compared with disease progression in the noninoculated plots. Consequently, the protective-inoculated plots had significantly lower overall disease severity than the noninoculated

The number of high grade fruits without symptoms produced in the protectiveplots during the experiments.

inoculated plots was significantly greater (97 and 37\% more in the 2002 and 2003 experiments, respectively) than in the control plots. Furthermore, of the total number of marketable fruits produced, including those of normal grade, those in the inoculated plots were superior to those in the control plots (Table 4).

When cucumber plants inoculated with ZYMV-2002 were grown in com-

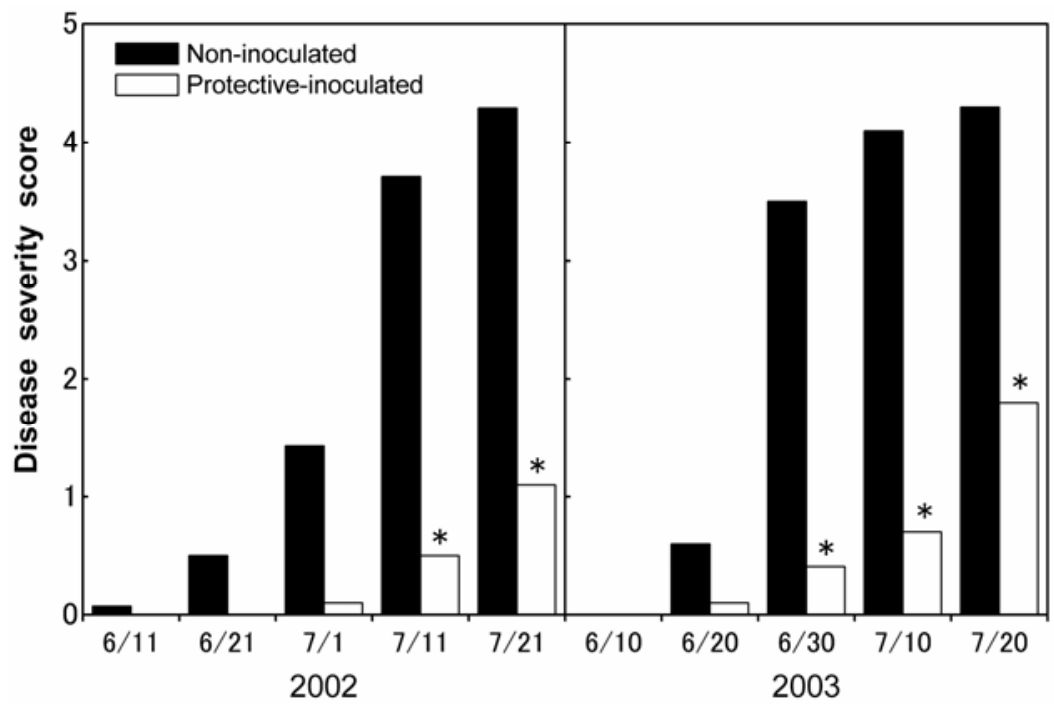

Fig. 4. Development of disease severity over time on protective- and noninoculated plants in two field experiments. Disease severity: $1=$ very mild mosaic or chlorotic spots; $2=$ mild mosaic or mild yellow mosaic; 3 = yellow mosaic without leaf distortion or malformation; $4=$ severe yellow mosaic with deformation of leaves and fruits; $5=$ grade 4 plus stunting and necrosis or wilting. Asterisks indicate a significant difference between two plots based on the Mann-Whitney $U$ test $(P=0.05)$.

Table 4. Comparison of marketable fruit produced in the protective- and noninoculated plots

\begin{tabular}{lccccc}
\hline & \multicolumn{4}{c}{ No. of marketable fruits ${ }^{\mathbf{a}}$} \\
\cline { 2 - 3 } \cline { 5 - 6 } Treatment & \multicolumn{2}{c}{$\mathbf{2 0 0 2}$ test } & & \multicolumn{2}{c}{$\mathbf{2 0 0 3}$ test } \\
\cline { 2 - 3 } \cline { 5 - 6 } Noninoculated & $55.9 * \mathrm{~b}$ & $29.4 *$ & & $75.7^{*}$ & $10.4 *$ \\
Protective-inoculated & 110.4 & 3.4 & & 104.0 & 0.7 \\
\hline
\end{tabular}

${ }^{a}$ Marketable fruits free of prominent viral symptoms and/or undesirable shape due to physiological factors: normal grade = fruit with chlorotic spots and/or slight malformation; high grade $=$ fruit with no visible viral symptoms.

$\mathrm{b}$ Asterisks indicate a significant difference between two values in a column based on the $t$ test $(P=0.05)$. mercial fields in Ujidawara and Kamo under the simultaneous occurrence of ZYMV, CMV, WMV, and PRSV in 2003, they were protected from infection by ZYMV and showed significantly lower disease severity than control plants (Table 5). In both experiments, ZYMV-2002 was detected in only a few plants in the control plot by RT-PCR analysis (Table 5). These plants were co-infected with ZYMV and WMV (data not shown).

\section{DISCUSSION}

Attenuated viruses have been obtained in various ways $(7,14)$. In this study, we obtained an attenuated ZYMV isolate, designated ZYMV2002, following cold treatment by maintaining diseased plants at 12.5 to $15^{\circ} \mathrm{C}$ for about 2 months. This method was first reported for Soybean mosaic virus (9), and since then this attenuated isolate has been widely used in black soybean (Glycine max (L.) Merr.)producing areas in Kyoto Prefecture $(8,10)$. In addition, cold treatment at such low temperatures has successfully produced several mild isolates of CMV, ZYMV, and Bean yellow mosaic virus $(11,12)$. Thus, cold treatment is potentially useful for generating mild strains, although it remains unknown whether mild isolates are derived from selection and/or mutation.

ZYMV-2002 did not induce any local lesions on $C$. quinoa; however, the isolate Z5-1 that it originated from caused chlorotic lesions. With other mild potyvirus isolates, no or unclear appearance of local lesions on C. amaranticolor has also been reported $(13,19)$. Therefore, if the ability of local lesion formation on C. amaranticolor or C. quinoa is associated with symptom attenuation, the isolation of variants using unclear-, deformedlesions, or single-plant after cold treatment might be more effective for selecting mild strains compared with isolation using ordinary lesions.

Table 5. Cross-protection effectiveness of the attenuated 2002 Zucchini yellow mosaic virus (ZYMV) isolate in commercial fields in two locations ${ }^{\mathrm{a}}$

\begin{tabular}{|c|c|c|c|c|c|c|c|c|}
\hline \multirow[b]{2}{*}{ Location } & \multirow[b]{2}{*}{ Plot } & \multirow{2}{*}{$\begin{array}{c}\text { Disease } \\
\text { severityc }\end{array}$} & \multirow{2}{*}{$\begin{array}{c}\text { Severe } \\
\text { wiltingd }^{\text {d } \%)}\end{array}$} & \multicolumn{5}{|c|}{ Infected plants $(\%)^{b}$} \\
\hline & & & & ZYMV-2002 & ZYMV & CMV & WMV & PRSV \\
\hline \multirow[t]{2}{*}{ Ujidawara } & Noninoculated & $3.0 * * * \mathrm{e}$ & $10.0 *$ & $4.0 * * *$ & $94.0 * * *$ & 24.0 & $78.0^{*}$ & 2.0 \\
\hline & Protective-inoculated & 1.2 & 0 & 100 & 0 & 38.0 & 92.0 & 0 \\
\hline \multirow[t]{2}{*}{ Kamo } & Noninoculated & $3.6 * * *$ & 0 & $2.0 * * *$ & $94.0 * * *$ & 2.0 & 64.0 & $26.0^{* * *}$ \\
\hline & Protective-inoculated & 1.1 & 0 & 98.0 & 0 & 4.0 & 58.0 & 0 \\
\hline
\end{tabular}

a Fifty randomly selected plants from each plot were surveyed 79 (Ujidawara) and 69 (Kamo) days after transplanting.

b ZYMV-2002 and ZYMV were detected by reverse transcriptase-polymerase chain reaction (RT-PCR), and Cucumber mosaic virus (CMV), Watermelon mosaic virus (WMV), and Papaya ringspot virus (PRSV) were tested by double-antibody sandwich enzyme-linked immunosorbent assay (DAS-ELISA).

${ }^{\mathrm{c}}$ Disease severity: 1 = very mild mosaic or chlorotic spots; 2 = mild mosaic or mild yellow mosaic; $3=$ yellow mosaic without leaf distortion or malformation; $4=$ severe yellow mosaic with deformation of leaves and fruits; $5=$ grade 4 plus stunting and necrosis or wilting.

${ }^{\mathrm{d}}$ Wilting followed by death.

${ }^{\mathrm{e}}$ Disease severity, and severe wilting and percentage of infected plants were statistically analyzed with the Mann-Whitney $U$ test, and Fisher's exact test or chi-square test of independence, respectively. * and *** indicate significant differences between two plots in the same location at $P=0.05$ and 0.001 , respectively. 
ZYMV-2002 produced very mild or no symptoms on cucurbit plants and had no detrimental effects on cucumber fruit yield or quality. In addition, plants inoculated with this isolate developed no synergistic symptoms when coinfected with other viruses in both greenhouse and field experiments. These results suggest that ZYMV-2002 would be a good alternative to isolate ZY95 because it would greatly reduce the risk of negative impact on fruit productivity that has occurred when the insufficient mild isolate ZY95 has been used for cross-protecting cucumber seedlings in commercial fields.

ZYMV-2002 appeared to have poor aphid-transmissibility in the greenhouse experiments. In fact, this isolate rarely spread in control plots in the fields. Lecoq et al. (13) suggested that the dissemination of poorly aphid-transmissible ZYMV-WK remained very limited and would depend upon the presence of another potyvirus to provide an efficient helper component. Since the commercial field studies were performed under the simultaneous occurrence of ZYMV, WMV, and PRSV, there was an opportunity for transmission of ZYMV-2002 to be assisted by the helper component of any one of these three potyviruses; however, this isolate was detected in less than $5 \%$ of plants not inoculated with it. Poor transmissibility is a desirable trait of attenuated viruses to minimize the risk of economic loss due to natural spread to other crops.

Comparison of the complete nucleotide sequences of ZYMV-2002 (GenBank accession no. AB188116) and parental isolate Z5-1 (AB188115) revealed 14 nucleotide differences, which resulted in seven amino acid changes (17). However, no point mutations have been observed in the FRNK motif of the HC-Pro gene affecting ZYMV symptom expression (4), the PTK and KLSC motif of the HC-Pro gene (15), or the DAG motif of the coat protein gene (1) affecting aphid transmission. Therefore, further studies are needed to determine the amino acid change(s) associated with reduced symptom expression and aphid-transmissibility.
Based on results from the greenhouse experiments, cross-protection induced by ZYMV-2002 might be affected by differences in properties of ZYMV strains and be incomplete in field conditions under high disease pressure. Breakdown of cross-protection tended to occur gradually in the inoculated research plots as ZYMV spread in the control plots. However, in the growers' fields, ZYMV-2002 provided complete cross-protection, although almost all control plants became infected with ZYMV. This might have been due to differences in properties between ZYMV strains used in experiments and the local dominant strains, and/or to differences in disease pressure and spatiotemporal disease progression between locations. Further field trials are required, in other regions and/or under conditions in which protective plants are widely and simultaneously introduced, to demonstrate the efficacy of ZYMV-2002.

\section{ACKNOWLEDGMENTS}

This study was performed through Special Coordination Funds for Promoting Science and Technology (Leading Research Utilizing Potential of Regional Science and Technology) of the Ministry of Education, Culture Sports, Science and Technology of the Japanese Government.

\section{LITERATURE CITED}

1. Atreya, P. L., Lopez-Moya, J. J., Chu, M., Atreya, C. D., and Pirone, T. P. 1995. Mutational analysis of the coat protein $\mathrm{N}$ terminal amino acids involved in potyvirus transmission by aphids. J. Gen. Virol. 76:265-270.

2. Clark, M. F., and Adams, A. N. 1977. Characteristics of the microplate method of enzyme-linked immunosorbent assay for the detection of plant viruses. J. Gen. Virol. 34:475-483.

3. Desbiez, C., and Lecoq, H. 1997. Zucchini yellow mosaic virus. Plant Pathol. 46:809829.

4. Gal-on, A. 2000. A point mutation in the FRNK motif of the potyvirus helper component-protease gene alters symptom expression in cucurbits and elicits protection against the severe homologous virus. Phytopathology 90:467-473.

5. Iwasaki, M., and Inaba, T. 1988. Viral wilt of cucumber plants grafted on squash rootstocks. Ann. Phytopathol. Soc. Jpn. 54:584-592.

6. Iwasaki, M., Yamamoto, T., and Inaba, T. 1996. Wilt of cucumber plants grafted on squash rootstocks caused by viruses. Bull. Shikoku Natl. Agric. Exp. Stn. 60:1-60

7. Kameya-Iwaki, M. 1994. Control of virus disease by attenuated viruses. Agric. Hortic. 69:137-142.

8. Kosaka, Y. 1999. Outlook and future research for cross-protection strategy to control virus disease. PSJ Biocontr. Rep. 6:61-65.

9. Kosaka, Y., and Fukunishi, T. 1993. Attenuated isolates of soybean mosaic virus derived at a low temperature. Plant Dis. 77:882-886.

10. Kosaka, Y., and Fukunishi, T. 1994. Application of cross-protection to the control of black soybean mosaic disease. Plant Dis. 78:339-341.

11. Kosaka, Y., and Fukunishi, T. 1997. Multiple inoculation with three attenuated viruses for the control of cucumber virus disease. Plant Dis. 81:733-738.

12. Kosaka, Y., Nakazono, E., and Natsuaki, T. 2001. Attenuated isolates of Bean yellow mosaic virus obtained by cold treatment. (Abstr.) Jpn. J. Phytopathol. 67:142.

13. Lecoq, H., Lemaire, M., and WipfScheibel, C. 1991. Control of zucchini yellow mosaic virus in squash by cross protection. Plant Dis. 75:208-211.

14. Lecoq, H., and Raccah, B. 2001. Crossprotection: Interactions between strains exploited to control plant virus diseases. Pages 177-192 in: Biotic Interactions in Plant-Pathogen Associations. M. J. Jeger and N. J. Spence, eds. CAB International, Wallingford, UK.

15. Peng, Y., Kadoury, D., Gal-On, A., Huet, H., Wang, Y., and Raccah, B. 1998. Mutations in the HC-Pro gene of zucchini yellow mosaic potyvirus: Effects on aphid transmission and binding to purified virions. J. Gen. Virol. 79:897-904.

16. Saiga, T., Fujiwara, M., Saitoh, H., Ohki, S. T., and Osaki, T. 1998. Comparative analysis for replication and movement of cucumber mosaic virus in Cucumis figarei and C. melo. Ann. Phytopathol. Soc. Jpn. 64:255-263.

17. Wang, W.-Q., Natsuaki, T., Kosaka, Y., and Okuda, S. 2004. Complete genome comparison of Zucchini yellow mosaic virus parental and attenuated strains. (Abstr.) Jpn. J. Phytopathol. 70:39-40.

18. Yarden, G., Hemo, R., Livne, H., Maoz, E., Lev, E., Lecoq, H., and Raccah, B. 2000. Cross-protection of cucurbitaceae from zucchini yellow mosaic potyvirus. Pages 349-356 in: Proc. EUCARPIA meeting on cucurbits genetics and breeding, 7th, Acta Hortic. 510. N. Katzir and H. S. Paris, eds. ISHS, Leuven.

19. Yeh, S.-D., and Gonsalves, D. 1984. Evaluation of induced mutants of papaya ringspot virus for control by cross protection. Phytopathology 74:1086-1091. 